\title{
Optimality Theory, Language Typology, and Universalist Metrics
}

\section{Geoffrey Russom*}

\begin{abstract}
In Russom (2011), I defended a universalist hypothesis that the constituents of poetic form are abstracted from natural linguistic constituents: metrical positions from phonological constituents, usually syllables; metrical feet from morphological constituents, usually words; and metrical lines from syntactic constituents, usually sentences. An important corollary to this hypothesis is that norms for realization of a metrical constituent are based on norms for the corresponding linguistic constituent. Optimality Theory provides a universalist account of relevant linguistic norms and deals effectively with situations in which norms conflict, employing ranked violable rules. Language Typology provides a universalist account of relevant syntactic norms. In this paper I integrate these independently grounded methodologies and use them to explain the distribution of constituents within the line, identifying a variety of important facts that seem to have escaped previous notice. Universalist claims are tested against meters from each of the major language types: subject-verb-object (SVO), subject-object-verb (SOV) and verb-subject-object (VSO). My findings are incompatible with the claim that "lines are sequences of syllables, rather than of words or phrases” (Fabb, Halle 2008: 11).
\end{abstract}

Keywords: verse structure; Universalist Metrics; Optimality Theory; Language Typology; literary universals; alliterative meter; iambic meter; Irish Gaelic meters; Old Germanic meters

Optimality Theory (OT) posits an inventory of universal constraints on linguistic form, expressed as violable rules (Prince and Smolensky 2004). Within a given language, OT rules are ranked in a hierarchy of influence. A rule will be violated if it conflicts with a rule of higher rank. Differences among languages are explained as ranking differences. There are two kinds of rules and both are typically formulated as prohibitions. Well-formedness rules prohibit departures from norms of linguistic structure. The NO-CODA rule prohibits closed syllables, for example, and the STRESS-TO-WEIGHT rule prohibits short stressed syllables. Faithfulness rules prohibit change to underlying forms,

* Author's address: Geoffrey Russom, Department of English, Brown University, Rhode Island 02912, USA.E-mail: geoffrey_russom@brown.edu. 
facilitating recovery of meaning from the acoustic signal. When a well-formedness rule conflicts with a faithfulness rule, there is no change if the faithfulness rule ranks higher. If the well-formedness rule ranks higher, the faithfulness rule is violated and the underlying form is changed. The language-specific hierarchies of OT are structured to select one and only one of the surface forms that could be derived from a given underlying form by the universal rules. OT has been most fully elaborated within phonology and morphology but has also proved useful within syntax (Kager 1999: 341-369).

Metrical rules differ in some ways from linguistic rules. Consider iambic pentameter. Its rules do not select one and only one surface form as a realization for the underlying pattern of five iambic feet. What metrical rules do is restrict mismatches to a metrical prototype (Youmans 1989). Several kinds of mismatch are typically permissible but the number of mismatches within a line is restricted. Each mismatch inhibits other mismatches nearby, and certain combinations of mismatches may be ruled out altogether (Kiparsky 1977). Restrictions on mismatch to a prototype can be formulated as violable rules that resemble OT rules but can be violated under different conditions and combine to exert their influence in an additive way. This approach turns out to be quite helpful in dealing with intricate metrical problems. I have found it most convenient to formulate metrical rules as norms that allow for exceptions at a cost in complexity. As we shall see, departures from these norms have detectable consequences.

My initial hypothesis for study of poetic form is that the constituents of a metrical prototype are abstracted from optimal linguistic constituents. For analysis of iambic pentameter, I posit metrical positions abstracted from syllables, metrical feet abstracted from words, and metrical lines abstracted from sentences (Russom 2011: 353-355; Russom 2017: 22-28). ${ }^{1}$ An important corollary to my initial hypothesis is that norms for realization of a metrical constituent are abstracted from norms for the corresponding linguistic constituent. Within this theoretical framework, it is obvious what constitutes an optimal match between an abstract metrical pattern and the language used to realize that pattern by a poet.

Item (1) is an optimal realization of the iambic pentameter prototype with its underlying metrical pattern notated below.

1 In the unmarked case, a line pattern can accommodate a typical sentence from the poet's stylistic register (Russom 2017: 15-19). Line patterns are marked to the extent that they fall short of typical sentence length. 
(1) Refíned / gourméts // demánd / supérb / cuisine.

$\mathrm{xS} / \mathrm{xS} / / \mathrm{xS} / \mathrm{xS} / \mathrm{xS}$

In the notation, "S" represents a strong position normally occupied by a stressed syllable and " $\mathrm{x}$ " represents a weak position normally occupied by an unstressed syllable. Foot boundaries are represented by a forward slash (/). The caesura is represented by a double slash (//). Each x position in (1) is realized as an unstressed syllable, each $S$ position is realized as a stressed syllable, each foot is realized as a word, and the line is realized as a sentence with subject-verb-object word order, the basic word order in Modern English. The caesura falls at the major syntactic break of the sentence, between the subject noun phrase (refined gourmets) and the predicate verb phrase (demand superb cuisine). The metrical location of this caesura, between positions four and five, is the unmarked location in iambic pentameter (Kiparsky 1977: 230).

All traditional meters employ the line, but the smaller constituents are optional (Russom 2011: 338-350; Russom 2017: 29-33). One Irish meter specifies the number of words per line but has no rules for syllable count or stress patterning (Carney 1989: 44-46). This meter employs feet but no metrical positions. The Serbo-Croatian decasyllable counts syllables but has no rules for syllable length, stress, or word count. This meter employs metrical positions but no feet. The meter of the Biblical psalms employs a line with no metrical positions and no feet. Adjacent lines in a Biblical couplet match one another in syntax and propositional semantics. These are the characteristic features of the sentence as distinct from the word and the syllable (Chierchia, McConnellGinet 1990: 6-7). In this parallelistic meter, each line of the couplet takes the adjacent line as its semantic-syntactic prototype. Lines within a couplet are complex to the extent that they differ syntactically and semantically.

In meters with a fixed prototype, the prototype incorporates optimal features of the relevant language and each non-optimal feature in a line constructed by the poet increases metrical complexity. In a meter preserved over a long period of time for its cultural value, the prototype may incorporate optimal features of the era in which the meter was born, and linguistic innovations of the poet's era may cause metrical complexity. Poets can fix certain features of the line arbitrarily, for example the number of feet or metrical positions. The most interesting metrical rules are based on native speaker intuitions, however, and normally operate below the horizon of consciousness, for the poet as well as the audience. In some meters there is a metrical domain between the foot and the line. The Old English line, for example, is divided into two verses, the first called the a-verse and the second called the b-verse. These metrical constituents are abstracted from two-word phrases below the level of the sentence. 
As defined within the field of Language Typology (Greenberg 1963), a prototypical sentence pattern has the normal word order of a declarative sentence with a lexical noun subject, a finite main verb, and a lexical noun object. Many features of a given language can be predicted from the normal order of these constituents. Like main verbs, prepositions govern objects and may assign special case forms to them. Prepositions are typically placed like finite verbs relative to their lexical objects. Finite verbs and prepositions are less prominent than the lexical objects they govern, having the weaker phrasal stress in stressbased phonological systems. Like prepositions in these respects are articles, demonstratives, auxiliary verbs, and other governors with largely grammatical function. They are less prominent than the lexical words they govern and the order of governor and governed tends to follow the order of verb and object (Dryer 2007). The three major language types are subject-object-verb (SOV), subject-verb-object (SVO), and verb-subject-object (VSO). These are the three possible types with the subject preceding the object.

Correspondences between sentence structure and the poetic line are highlighted by sound echoes like rhyme and alliteration, which are strongly associated with linguistic prominence. The last stressed word of a prototypical sentence has prominent phrasal stress in SVO languages like English. Linefinal rhyme is ideally suited to a stress-based SVO language. In SOV languages like Proto-Germanic, the word at the end of a prototypical sentence is a finite verb with relatively low prominence; and there is a rule against alliteration on the last stressed syllable of the line in all the meters that originated in the late Proto-Germanic era, which include Old English, Old Norse, Old Saxon, and Old High German meters (Sievers 1893: 38). ${ }^{2}$ The first word in a late ProtoGermanic phrase is normally the most prominent one; and in each verse of the Old Germanic line, alliteration is required on the first word with metrically significant stress (Russom 1998: 65-69). VSO languages like Old Irish have the weakest stress on the first word of a prototypical sentence. In Old Irish regulated word-foot meter, the line is composed of two verses, resembling Old Germanic meter in this and other respects, such as employment of alliteration and of metrical feet normally realized as words (Travis 1973). In the Irish meter, however, the first alliteration normally falls on the second stressed word. Alliteration is permissible on the first stressed word but is not required. Alliteration usually comes after the first stress in an otherwise quite different Irish meter as well, one in which the line does not divide into two

2 This rule ranks lower than the rule requiring an alliterative link between the a-verse and the b-verse. When the last stress of the line is the only stress in the b-verse, it must alliterate. See item (5) for discussion of b-verses with one stress. 
verses (Lehmann, R., Lehmann, W. 1975: 134-137, 144-145). As with stressbased SVO languages, VSO languages like Irish have prominent phrasal stress on lexical objects in sentence-final position. End rhyme is well suited to a line abstracted from a prototypical Irish sentence. It is not surprising that Irish syllabic poets were among the first in Europe to develop schemes of end rhyme that regulated stressed root syllables (Murphy 1961: 13-17). Correspondences between the line and the sentence provide independent evidence that the prototypical sentence patterns posited by typologists are encoded in human linguistic systems and are accessible in real time with automatic facility.

A prototypical Old English verse has two metrical feet abstracted from optimal words. Item (2) provides representative examples from Beowulf. ${ }^{3}$

(2) (a) wuldres / waldend (183a) 'the lord of glory' (Sx/Sx)

(b) bēagas / dōelde (80b) 'distributed rings' ( $\mathrm{Sx} / \mathrm{Sx})$

Example (2a) is an a-verse, the first verse of its line. Example (2b) is a b-verse placed at the end of its line. In these optimal verses, each S position is realized by a stressed syllable of normal length, ${ }^{4}$ each $\mathrm{x}$ position is realized by an unstressed syllable, and each word has the optimal stress pattern for Old English, which is well known to be trochaic (Dresher, Lahiri 1991). ${ }^{5}$

Sievers (1893) sorted verses with acceptable linguistic patterns into categories called verse types. His taxonomy has been widely used as a guide to the metrical facts, but he did not claim to have formulated general rules for the meter. Sievers did discover important trends within particular types. These findings can be captured with violable rules that apply across the board to all types. Consider for example rules R1-R8, which apply some universal

3 All Old English examples are cited from Fulk, Bjork, and Niles (2008), with suppression of diacritics not required for scansion.

4 In Old English meter there are no positions abstracted from short stressed syllables, which violate the universal STRESS-TO-WEIGHT rule. Such non-optimal syllables sometimes share an $S$ position with an unstressed syllable (matching normal length) and sometimes occupy a position by themselves (matching syllable count in the prototype). See Russom (1998: 97-117).

5 By the late Middle English period, the literary language was flooded with iambic words borrowed from France and unstressed inflectional endings were rapidly being lost from Old English trochaic forms. Indispensable functions of the old endings were usually shifted to unstressed monosyllabic words placed before the new stressed monosyllables, which had no inherent word rhythm. The French iamb replaced the trochee as optimal because it was equally suitable for iambic words and for closely bound iambic word groups. Such word groups are treated much like iambic words by Shakespeare (Kiparsky 1977: 206-11). 
principles of verse construction to Old English meter. These rules are also valid for the cognate Old Germanic meters in Old Norse, Old Saxon, and Old High German.

R1. An optimal line has the falling prominence contour of a prototypical SOV sentence, which ends with its least prominent constituent, a finite verb. Finite verbs normally appear in a non-alliterating location at the end of the line.

R2. The verse normally has the falling prominence contour of an SOV phrase, with the most prominent stressed word preceding any stressed word of lesser prominence.

R3. An optimal verse has two feet with the optimal word pattern (see R4 and R5). The optimal verse establishes norms for all verses, including a norm of four metrical positions and a norm of two primary word stresses (with no other stresses).

R4. A foot is normally realized as a word. There are foot patterns for compounds and unstressed function words as well as for stressed simplexes. ${ }^{6}$

R5. The optimal foot pattern corresponds to the optimal trochaic word pattern, which has a long stressed root syllable followed by an unstressed inflectional syllable.

R6. A metrical position is normally occupied by one syllable. Elision and resolution add to complexity.

R7. All syllables of stressed words must occupy metrical positions, including any unstressed syllables such as inflectional endings (a rule of highest rank).

R8. Unstressed prefixes and function words normally occupy metrical positions but may occur as extrametrical syllables, subject to well-defined constraints (Russom 1998: 45-59).

6 Every native word has a corresponding foot pattern, except for large compounds that fill a whole verse, with one constituent in each foot. The following examples of word patterns are followed by the corresponding foot patterns in parentheses: ond 'and' ( $\mathrm{x})$, oppe 'or' (xx), gōd 'good' (S), dryhten 'lord' (Sx), feohgift 'treasure gift' (Ss), sorhfulne 'sorrowful', acc. sg. (Ssx), middangeard 'middle earth' (Sxs), and sibbegedryht 'kindred band' (Sxxs). A lower-case " $\mathrm{s}$ " notates a metrical position normally occupied by a syllable with secondary word stress. Vowel length is marked by a macron, as in $g \bar{o} d$. A word boundary within a foot is marked by a colon. 
Metrical complexity has detectable consequences. All other things being equal, a mismatch will restrict the frequency of verses in which it occurs. An important aid to assessment of metrical complexity is the principle of closure, a universal tendency to restrict complexity toward the end of a metrical unit (Hayes 1983: 373). In Old English poetry, the less complex verses tend to appear at the end of the line, as b-verses; and the more complex verses tend to appear at the beginning, as a-verses. Assessing complexity can be tricky because metrical rules sometimes conflict with one another, like the rules of Optimality Theory. In such cases we need to determine which rule exerts the strongest influence.

To see how complexity is assessed, we begin with two metrically simple verses, appropriately classified as type A1 by Sievers. Alliterating syllables are in boldface. The proportion of a-verses to b-verses in Beowulf is specified within parentheses to the right.

(3) (a) aldrum / nēðdon (538a) Sx/Sx, type A1 (17:89)

'risked their lives'

(b) scyldas / bōeran (2850b)

'carried shields'

Examples (3a) and (3b) obey most of the rules. In both, a finite main verb follows a more prominent word that bears the alliteration (R2) and there are two primary word stresses, with no other stresses (R3). Each foot is realized as a single word (R4) and has a trochaic pattern corresponding to the optimal word pattern (R5). Each metrical position is realized as a single syllable, with no elision or resolution (R6). All syllables of stressed words occupy metrical positions (R7) and there are no extrametrical syllables (R8). Although example (3a) is not very complex, its placement in the a-verse makes it more complex than (3b), which situates its finite verb in a line-final location where alliteration is ruled out (R1). Verses like those in item (3) appear most often in the closing half of the line. There are only 17 a-verse instances like (3a), as compared with 89 b-verse instances like (3b). ${ }^{7}$

Linguistic rules applying at higher levels of structure can modify the effects of lower-level rules. The most prominent stress assigned at word level can be

\footnotetext{
Every effort has been made to exclude from the verse counts instances with irrelevant features that would obscure the effects of the features under inspection. The counts are from my electronic scansions, which have been available gratis since 1998. Updated copies of these scansions and instructions for their use can be requested at my email address, currently geoffrey_russom@brown.edu.
} 
subordinated by higher-level rules applying within small phrases. In Modern English phrases like òld mán, the primary word stress of the adjective is subordinated to the primary word stress of the noun. Small phrases can be affected by rules applying at the level of the clause or sentence, for example by the nuclear stress rule, which subordinates every stressed syllable before the final stress. Within the Old English line, similarly, line-level rules take precedence over verse-level rules, which in turn take precedence over foot-level rules.

Consider example (4a), which ends with a lexical noun but is otherwise like the verses in item (3).

(4) (a) lēofne / pēoden 34b

Sx/Sx $(198: 178)$ 'beloved lord (acc. sg.)'

(b) hrēow on / hreðre 2328a

$\mathrm{S}: \mathrm{x} / \mathrm{Sx}(84: 17)$

'sorrow in the heart'

(c) forð on/sendon $45 \mathrm{~b}$

S:x/Sx (8:43)

'sent forth'

Realizations like (4a) are less strongly attracted to the b-verse than the realizations in item (3), which end with a finite verb. In (4b), which also ends with a lexical noun, the first trochaic foot is realized as group of constituents rather than as a single word. This violation of $\mathrm{R} 4$ has an additive effect, further inhibiting placement in the b-verse. Like (4b), (4c) has a constituent group in the first foot but it ends with a finite verb, satisfying R1. In realizations like (4c), the violation of foot-level R4 is overridden by conformity to line-level R1, which creates a strong attraction to the $b$-verse.

Example (5a) is a type $\mathrm{C}$ verse with an unstressed function word in the first foot and a compound word in the second foot. ${ }^{8}$

(5) (a) on / bēorsele 492a

$\mathrm{x} /$ Ssx, type C (363:124)

'in the beer hall'

(b) on / bearm scipes 35b

$\mathrm{x} / \mathrm{S}: \mathrm{sx}(25: 83)$

'into the hold of the ship'

(c) Swā / rīxode 144a

$\mathrm{x} / \mathrm{Sxx}(12: 4)$

'thus he ruled'

\footnotetext{
8 Extrametrical unstressed syllables create irrelevant metrical complexity in types A and D, but not in type C (Russom 1998: 45-59). Instances with extrametrical syllables are included in the counts for type C. Realization of a light $\mathrm{x}$ or $\mathrm{xx}$ foot as a prefix does increase complexity in type $\mathrm{C}$, and instances with this irrelevant feature are excluded.
} 
Verses like (5a) have one primary word stress and one secondary word stress. Such verses realize the second foot as a word, in accord with R4, but fall below the normal weight of two primary word stresses, violating R3. Violation of verse-level R3 overrides conformity to foot-level R4, and realizations like (5a) have highest frequency in the a-verse. Realizations like (5b) end with an independent noun or adjective rather than with the secondary constituent of a compound. They realize the second foot as a constituent group, violating R4, but have the optimal weight of two primary word stresses. Here conformity to the verse-level weight norm in R3 overrides the violation of foot-level R4. Realizations like (5b) have highest frequency in the b-verse. In the light type $\mathrm{C}$ pattern realized by $(5 \mathrm{c})$, the second foot is occupied by a trisyllabic finite verb of weak class II with no stress on the medial syllable, and the verse has only one stress. This violation of R3 inhibits placement of realizations like (5c) in the b-verse. Although $(5 \mathrm{c})$ has a finite verb in line-final position, the verb alliterates, contrary to R1. Realizations like (5c) are not strongly attracted to the b-verse.

In type Da verses like (6a-b), the second foot has the same Ssx pattern that appears in (5a-b), but the first foot contains an $\mathrm{S}$ position. ${ }^{9}$

(6) (a) scearp / scyldwiga 288a 'keen shield-warrior'

(b) sweord / Bīowulfes 2681b 'the sword of Beowulf'

(c) secg / wìsade 208b 'the man led the way'
S/Ssx, type Da $(26: 4)$

S/Ssx $(10: 14)$

S/Sxx $(0: 38)$

Type Da verses like (6a) are heavy relative to the norm of two primary word stresses because they have an additional secondary stress in the Ssx foot. Due to this violation of $\mathrm{R} 3$, such realizations have highest frequency in the a-verse. In type $\mathrm{C}$, as we just observed, realizing the second foot as a word group brings the verse up to normal weight. In type $\mathrm{Da}$, realizing the second foot as a word group makes the verse even more abnormally heavy. Word groups ending in a noun or adjective occupy the second foot in only three instances of type Da, all of which are a-verses (896a, 1485a, and 3077a). Secondary stress is reduced to tertiary stress in Old English compound proper names. In example (6b), reduction of the secondary stress in Biowulfes brings a type Da verse closer to

$9 \quad$ Examples with resolution or extrametrical syllables are excluded (as in type A1). Expanded Da verses are excluded because their abnormal length of five positions violates R3 and creates an irrelevant attraction to the a-verse. 
normal weight. Realizations like (6b) have enhanced frequency in the b-verse. In the lightest D subtype, represented by $(6 c)$, the second foot is realized as an Sxx finite verb of weak class II. As we observed, type C realizations like (5c) have subnormal weight and alliteration on the finite verb. Most are a-verses. Type D realizations like (6c) have normal weight, realize each foot as a word, and have the finite verb in a non-alliterating location. Here R1, R3, and R4 work together to create a strong additive effect. All 38 realizations like (6c) are b-verses. ${ }^{10}$

Alliteration is often regarded as an ornamental feature distinct from the metrical pattern of the line. This view has recently been endorsed by Cornelius (2017: 37, 62), who discusses its history in studies of poetic form. Within the universalist theory employed here, alliteration is defined as a metrical prominence abstracted from linguistic prominence in a prototypical sentence pattern. Rhyme is defined in the same way. On this view, rhyme and alliteration are included within the abstract line pattern just as phrasal stresses are included within the sound pattern of the sentence. As we have seen, rules based on sentence structure play a very prominent role in Old English meter. If our language-based approach is valid, we would expect to find similar rules in the iambic meters that came into fashion as SVO became the predominant word order and rhyme added metrical prominence to the last $S$ position of the line.

Sir Gawain and the Green Knight, a poem of the late fourteenth century, consists of narrative passages in Middle English alliterative verse followed by small rhymed passages that summarize the preceding action. ${ }^{11}$ The transition from alliteration to rhyme is illustrated in item (7).

(7) "Gladly I wolde alliterative verses

See that segge in sight and with himself speke

Resoun."

"bob"

To knightes he cast his iye

"wheel"

And reled hem up and doun;

He stemmed and con studie

Who walt there most renoun.

\footnotetext{
10 Verse placement and overall frequency provide two ways to highlight metrical norms. The two-word norm, for example, can be highlighted by frequency in the a-verse even when violation of higher-level norms inhibits placement of a two-word realization in the b-verse, as with examples (5a) and (6a).

11 For comprehensive philological analysis of Gawain and similar poems, see Putter, Jefferson, Stokes (2007). Middle English lines are cited from Putter, Stokes (2014), which partially modernizes the manuscript spellings.
} 
"I would gladly / see that man with my own eyes / and with him speak / sense." / He cast his eyes on the knights / and rolled them up and down. / He paused and began to ponder / who there had most renown" (lines 225-31).

All the poet's alliterative lines have a trochaic constituent in line-final position (Yakovlev 2008: 142-154). Archaic SOV order is still used with significant frequency to satisfy the strict requirements of the b-verse, but that frequency falls off sharply in the a-verse, where SVO order predominates (Russom 2017: 134-258). Each rhymed passage begins with a short line consisting of one iambic foot, called the "bob." 2 Then comes the "wheel", which consists of four lines in iambic trimeter $(\mathrm{xS} / / \mathrm{xS} / \mathrm{xS})$. All 101 bobs in the poem begin with an unstressed syllable. Rising rhythm is obligatory at the point of transition. At the end of the trimeter line, where the principle of closure applies, the Gawain poet makes a special effort to realize the iambic foot as an iambic word (Russom 2017: 262-271). The same kind of effort can be detected in iambic pentameter. In a sample of 7339 lines from Milton's blank verse, Youmans (1989) discovered that the poet will depart from ordinary word order to place an iambic word at the end of the pentameter line, but seldom to remove an iambic word from that position. Youmans concluded that "Milton's prototype for the iambic foot is the iambic word" (1989: 362).

Transitioning successfully from the line-final trochee of an alliterative passage requires rather strict conformity to the iambic prototype at the beginnings of metrical units, in the wheel as well as the bob. Compared with Shakespeare, Milton, or Pope, the Gawain poet allows more extrametrical unstressed syllables into the line, but these are placed with care. Use of extrametrical syllables is restricted before the first foot of the trimeter and also before the third foot, where the principle of closure applies. The best site for extrametrical syllables is before the second foot, after iambic rhythm has been established but before the closure.

In Old English SOV meter, as we have seen, the influence of a metrical norm depends on the level at which it applies. SVO iambic trimeter is a very different form, but its norms also exert greater influence at higher levels. Realization of the foot as an iambic word is desirable, but it is still more

\footnotetext{
12 I analyze the bob as a one-foot line because it rhymes, like the four lines of the wheel. Even smaller rhymed lines consisting of monosyllabic words can be found in an Irish stanzaic form that exploits the abnormal bluntness of such lines for satiric effect. Strict rules of the form make it clear that the monosyllabic line is simultaneously a foot and a metrical position (Russom 2017: 33).
} 
desirable to realize the line as a sentence (or as a clause transparently derived from a sentence). This occurs in about $60 \%$ of the 404 trimeters. $^{13}$

In a prototypical English sentence with SVO order, the lexical subject is more prominent than the main verb; and the lexical object at the end, which bears nuclear stress, is more prominent than the lexical subject. The optimal prominence contour for the trimeter is accordingly 231, where 2 is intermediate, 3 is lowest, and 1 is highest. Preference for a 231 contour shows up in patterns of optional alliteration, which can be found in about half of the trimeter lines. Table I shows frequencies for placement of alliteration on the three S positions.

Table I. Patterns of alliteration on the S positions of the trimeter (xS//xS/XS)

\begin{tabular}{|l|l|l|}
\hline First and last $S(A X A):$ & 75 instances & best match for 231 contour \\
\hline All S positions $(A A A):$ & 52 instances & middle S not deemphasized \\
\hline Last two S positions $(X A A):$ & 45 instances & opening S deemphasized \\
\hline First two S positions $(A A X):$ & 32 instances & closing S deemphasized \\
\hline Total lines with alliteration: & 204 & \\
\hline Total trimeter lines: & 404 & \\
\hline
\end{tabular}

As Kiparsky observes (1973: 231), alliteration is universally linked to linguistic prominence. Placement of alliteration provides good evidence for relative metrical prominence in the iambic trimeter prototype, a metrical analogue of sentences like Gawáin // admits / deféat.

In about $25 \%$ of the trimeters, the Gawain poet departs from ordinary word order to place the rhyming word at the end of the line. In another $7 \%$, marked word order that has no effect on rhyme placement optimizes foot structure, filling empty $\mathrm{x}$ positions or moving stressed syllables from $\mathrm{x}$ positions to $\mathrm{S}$ positions. ${ }^{14}$ In items (8) through (11), I consider all other lines with a marked word order that has no effect on rhyme placement, adapting the methodology of Youmans (1989) to a different metrical problem. In every one of these lines, marked word order brings the prominence contour closer to the 231 norm, resituates an extrametrical syllable before the second foot, or performs both functions at once.

13 The examples in items (8) through (11) are representative. Most are realized as sentences like (8a) or as clauses like (8b).

14 Lines 19, 82, 84, 127, 231, 465, 737, 738, 900, 1077, 1146, 1207, 1240, 1288, 1315, 1401, 1579, $1748,1749,1791,1918,2065,2115,2138,2158,2138$, and 2476. General principles of scansion for the trimeter are presented in Russom (2017: 262-270). 
Examples (8a) through (8e) illustrate the poet's use of object movement to optimize the line pattern. The objects as they stand in the manuscript are italicized. The bracketed instances, marked with a superscript ' 1 ', show the unmarked positions from which the objects have been moved.

(8) (a) Burnes him broght [him $]^{1}$ to bent 1599

[men brought him to the field]

(b) When he hit schuld(e) schew(e) [hit] ${ }^{1}$ for scham(e) 2504

[when he had to show it for shame]

(c) The lappes thay laus(e) [the lappes] ${ }^{1}$ bihind(e) 1350

[they remove the folds at the rear]

(d) Much mirth(e) he mas [much mirth] ${ }^{1}$ withall(e) 106

[he makes much mirth as well]

(e) Much solac(e) set thay [much solace] ${ }^{1} \operatorname{sam}(\mathrm{e}) 1318^{15}$

[they made much joy together]

(f) Thagh I nad(e) oght of youres $1815 \quad\left({ }^{*}\right.$ Thagh noght had I of youres)

[though I did not have anything of yours]

(g) Couples huntes of kest [couples] ${ }^{1} 1147$

[huntsmen cast off leashes (from their dogs)]

In example (8a), the bracketed instance of him would have been an extrametrical syllable in the dispreferred location before the closing foot. In fronting the italicized instance of him, the poet has resituated the extrametrical syllable before the middle foot, its best location. The same kind of movement occurs in example (8b) and places the extrametrical pronoun hit in its best location. In the Gawain manuscript, unstressed $e$, when not purely scribal, represents a weak schwa vowel that was gradually being eliminated from English. This non-optimal vowel is rarely necessary in the rhymed lines. Parenthesized $e$ should be ignored in (8b) and in subsequent examples. ${ }^{16}$ Weak $e$ is still syllabic when protected by a word-final consonant, however, as in inflections like -es

15 Fronting sometimes triggers other kinds of movement. In (8e), inversion of subject and verb avoids adjacent stress mismatches. Translations follow the unmarked word order, ignoring such secondary movement.

16 In the trimeter, as in iambic pentameter, the first weak position may be left empty but all other metrical positions must be filled. Weak final -e appears hundreds of times in the 404 trimeter lines but would be required to fill a position only in lines $34,532,586,687,736,1078$, $1177,1316,1769,1868,2136$, and 2357 . When ordinary syllables are available for weak positions, constraints on word placement ignore weak final $e$. Lexical amphibrachs with final $-e$ are concentrated in the closing foot, for example, like iambic words (Russom 2017: 263-66). 
and -ed. In examples (8c) through (8e), fronting enhances the 231 contour, placing a prominent object in the first foot and a finite verb in the second foot. In (8c), fronting of the lappes also results in best placement of the extrametrical inflection -es. When there is little or no metrical improvement, the poet defaults to ordinary word order, as in example (8f). The poet does not use the starred word order to the right because it would not improve placement of unstressed syllables and would not significantly change the relative prominence of the first two feet, neither of which has a prominent syllable on its $\mathrm{S}$ position. ${ }^{17} \mathrm{In}(8 \mathrm{~g})$, both couples and huntes are trochaic lexical nouns. Ordinary word order would also place prominent noun roots in both feet, but since couples is rendered still more prominent by alliteration, object fronting improves the metrical contour. ${ }^{18}$

In some trimeter lines, object fronting to the first available location, marked by the bracketed expression with a superscript '2', would place the rhyme word correctly but would miss an opportunity for metrical improvement.

(9) (a) This dint that thou [this dint $]^{2}$ schal driv(e) [this dint $]^{1} 389$ [that you will strike this blow]

(b) That chapel er(e) he myght [that chapel] ${ }^{2} \operatorname{sen}(\mathrm{e})\left[\right.$ that chapel] ${ }^{1} 712$ [before he could see that chapel]

(c) Such chaffer and ye [such chaffer] ${ }^{2}$ draw(e) [such chaffer $]^{1} 1647$ [if you acquire such merchandise]

(d) My lif thagh I [my lif] ${ }^{2}$ forgo [my lif] ${ }^{1} 2210$ [though I forfeit my life]

(e) A semloker that e(ve)r he [a semloker] ${ }^{2} \operatorname{sy}(\mathrm{e})$ [a semloker] ${ }^{1} 83$ [that he ever saw a seemlier (one)]

(f) The bok(e) as I [the boke $]^{2}$ herd(e) [the book $]^{1}$ say 690 [as I heard the book say]

In examples (9a-e), the poet moves a direct object farther to the left, immediately before the subordinating conjunction. This highly marked word order is used only to optimize metrical form. The additional movement places a lexical

17 As in Old English poetry, three salient prominence distinctions can be identified with textual evidence (Sievers 1893: 41-46; Momma 1997; Russom 2009). Lexical nouns and adjectives generally have the most prominent phrasal stress. Finite main verbs and some adverbs generally have intermediate prominence. Function words have lowest prominence. Apparent instances of alliteration on function words must often be ignored for normal scansion.

18 In Old Germanic meter, similarly, assignment of alliteration mimics a stress assignment rule that subordinates the following stress (Russom 1998: 65-86). 
noun or adjective root in the first foot and a less prominent word in the second foot. ${ }^{19}$ Example (9f) shows additional movement of a logical subject raised to object position, which improves the prominence contour in the same way. In (9a) and (9e), additional movement also creates an optimal AXA pattern of alliteration.

Item (10) illustrates placement of prepositional phrases to optimize the meter. $^{20}$

(10)(a) To soper thay yed(e) [to soper $]^{1}$ as swyth(e) 1400

[they went to supper in haste]

(b) Thurgh playnes thay pass(e) [thurgh playnes] ${ }^{1}$ in spac(e) 1418

[they pass through plains in due course]

(c) By sythes has wont [by sythes] $]^{2}$ ther(e)inn(e) [by sythes] ${ }^{1} 17$

[has lived therein at times]

(d) To knightes he cast [to knightes] ${ }^{2}$ his iy(e) [to knightes] ${ }^{1} 228$

[he cast his eyes on the knights]

(e) To bed yet er(e) [to bed $]^{2}$ thay yed(e) [to bed $]^{1} 1122$

[Yet before they went to bed (they discussed their plans)]

(f) For woth(e) that thou [for wothe] $]^{2}$ ne wond(e) [for wothe] ${ }^{1} 488$

[that you do not retreat because of danger]

(g) By non way that he [be non way $]^{2}$ myght [be non way $]^{1} 1045$

[that he could in no way (do so)]

In $(10 \mathrm{a}-\mathrm{d})$, fronting the prepositional phrase shifts the extrametrical unstressed syllables of soper, playnes, sythes, and knightes from the dispreferred location before the closing foot to the best location. In these lines fronting also places a lexical noun root on the first $\mathrm{S}$ position and a less prominent finite verb root on the second $S$ position, improving the prominence contour. Examples (10e-g) move a prepositional phrase before a subordinating conjunction. In (10e-f), this highly marked construction situates a prominent noun in the opening foot and a less prominent word in the middle foot. In (10f), movement also creates the optimal AXA alliterative contour. In (10g), way is subordinated to

19 In (9e), $e(v e) r$ scans as a monosyllable, like the form spelled $e$ 'er in later English poems; and similarly with $n e(v e) r$ in (11b). These words must scan as monosyllables in some alliterative lines as well (Russom 2017: 141-142).

20 Fronting from the first available location does not yield significantly more unusual word order in lines $35,178,340,809,1102,1666,1667,1718,2159,2238$, and 2258. I exclude these lines from item (10). The frontings improve the meter, but with no significant cost in syntactic complexity. 
non, which occupies the first $\mathrm{S}$ position, and non is more prominent than the conjunction that, which occupies the second S position. ${ }^{21}$

The examples in item (11) show fronting of constituents other than objects and prepositional phrases. ${ }^{22}$

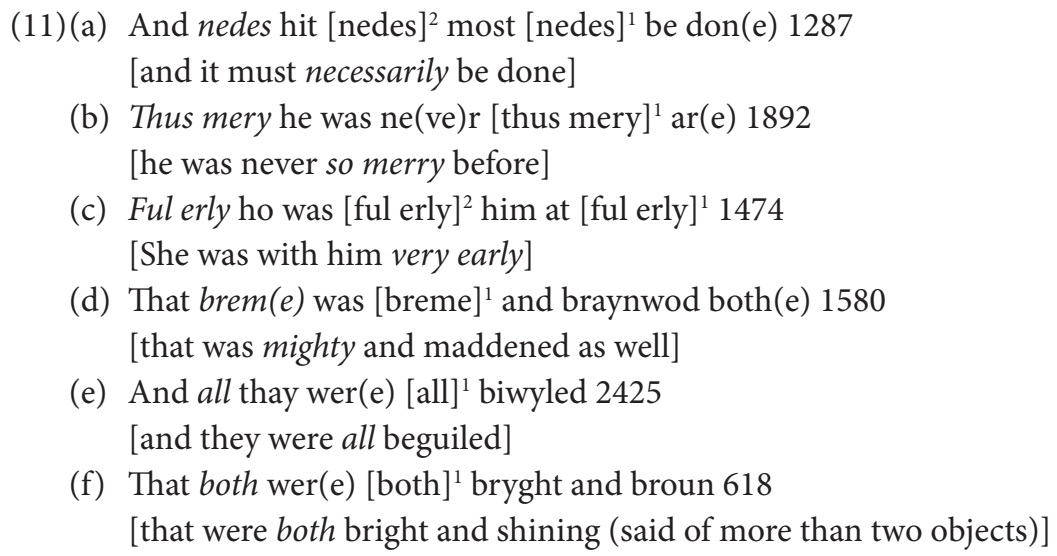

In (11a-c), fronting of adverbials improves the prominence contour and the placement of extrametrical syllables. In (11d), fronting of a predicate adjective performs the same two functions. Since all vowel-initial stressed syllables alliterate with one another, fronting creates AXA alliteration in (11c). In (11e), which has no extrametrical syllables, fronting of all improves the prominence contour. In (11f), both is moved from proclitic position to an S position between unstressed words, enhancing its linguistic and metrical prominence. A more prominent both provides salient alliteration with bright and broun, creating an AAA alliterative pattern from the less favored pattern XAA.

If the Gawain poet uses marked word order to avoid certain departures from the trimeter prototype, we would expect the same departures to be avoided if possible by techniques that are more difficult to use and less conspicuous within a single line - paraphrasing and substitution of synonyms, for example. Detailed analysis of such techniques would take us far beyond the scope of this article, but the influence of the prototype shows up in total frequencies. Table II summarizes syllable placement and prominence in all 404

21 Note that non would also appear on an S position in ${ }^{\star}$ that he be non way myght. An audience expecting stress on $S$ positions would subordinate way in this word order as well, and the second $\mathrm{S}$ would then be more prominent than the first.

22 Here as well I ignore movement that does not create a more highly marked word order. Excluded from item (11) are lines 465, 534, 666, 1206, 1789, 1816, 1976, and 2305. 
trimeter lines. ${ }^{23}$ Separate counts are provided for verses with the prominence contours 231, 321, and 221. The 221 category is for verses with no salient prominence distinction between the syllables on the first two $S$ positions (as defined in note 17).

Table II. The boldface heading at the left of each row specifies a prominence contour. The boldface heading above each column specifies the number of syllables before the first, second, and third S positions of the trimeter.

\begin{tabular}{|r|r|r|r|r|r|r|r|r|r|r|r|}
\hline & $\mathbf{1 / 1 / 1}$ & $\mathbf{1 / 2 / 1}$ & $\mathbf{2 / 1 / 1}$ & $\mathbf{1 / 1 / 2}$ & $\mathbf{0 / 2} / \mathbf{1}$ & $\mathbf{0 / 1 / 1}$ & $\mathbf{1 / 2 / 2}$ & $\mathbf{1 / 3 / 1}$ & $\mathbf{0 / 1 / 2}$ & rare & totals \\
\hline $\mathbf{2 3 1}$ & 109 & 56 & 15 & 6 & 6 & 6 & 3 & 3 & 1 & 4 & 209 \\
\hline $\mathbf{3 2 1}$ & 53 & 25 & 3 & 7 & 4 & 3 & 4 & 1 & 3 & 5 & 108 \\
\hline $\mathbf{2 2 1}$ & 44 & 27 & 5 & 3 & 2 & 2 & 0 & 2 & 1 & 1 & 87 \\
\hline totals & 206 & 108 & 23 & 16 & 12 & 11 & 7 & 6 & 5 & 10 & 404 \\
\hline
\end{tabular}

The trimeter provides especially informative evidence for our language-based approach because it has just one foot for each word in a prototypical SVO sentence: an initial foot with intermediate prominence, a middle foot with lower prominence, and a closing foot marked as most prominent by rhyme (and often highlighted by alliteration as well). Our sample of 404 lines is quite sufficient and can readily be surveyed by anyone who reads Middle English. ${ }^{24}$ Departures from the prototype clearly restrict frequency. Lines with a 231 contour have nearly twice the frequency of lines with a 321 contour (209 total instances versus 108). Lines free of extrametrical syllables - the 206 total instances in the $1 / 1 / 1$ column - are more common than all other lines combined. Lines with one extrametrical syllable placed before the second S (108 instances) are more than four times as common as lines with the extrametrical syllable before the first $S$ (23 instances) or the third S (16 instances). As in iambic pentameter, lines with every position filled are strongly preferred to "headless" lines with the first weak position left empty (28 total instances of $0 / 2 / 1,0 / 1 / 1$, and $0 / 1 / 2$, plus 2 instances of $0 / 3 / 1$ from the "rare" category). All

23 Relative prominence is assessed as in items (8) through (11). See note 17. I ignore weak -e unless it must fill a position, as before. See note 16 . To declutter the table, I have combined in one column frequencies for the rare patterns $2 / 2 / 1$ (lines $341,1842,2186,2477), 0 / 3 / 1$ (2387, 2454), 2/2/2 (840, 2478), 1/3/2 (1452), and 2/1/2 (1577).

24 Although trimeter lines are not common in Middle English, my findings might generalize to other forms of Middle English rhymed poetry. This is a topic for further research requiring new methods of verification. My scansions of the trimeters are now available gratis to researchers (see note 7). 
these metrical facts are explained by the hypothesis that the trimeter prototype corresponds to the sentence pattern of Gawáin // admits / deféat. This hypothesis also explains why iambic words are concentrated in the closing foot, why $60 \%$ of the trimeters are sentences or clauses, and why metrical positions are so seldom realized as non-optimal weak $e$. As we have seen, a variety of metrical facts in SOV and VSO meters can be explained by our more general hypothesis that the metrical constituents of the prototype are abstracted from optimal linguistic constituents.

Fabb and Halle (2008: 11) assume that "lines are sequences of syllables, rather than of words or phrases." Such an initial hypothesis may not seem too implausible when we confine attention to the kinds of poetry most thoroughly analyzed in Western scholarship: Vedic Sanskrit poetry, Sappho's lyrics, Homer's dactylic hexameter, and Shakespeare's iambic pentameter, for example. As Watson observes (2005: 98), it is the "lack of regular meter", as commonly understood, that seems most jarring to metrists when they encounter the Hebrew psalms. Although Fabb and Halle concede that lines of Hebrew poetry are parallel syntactic constituents rather than sequences of syllables, they assign the psalms to a category of non-metrical poetry that includes free verse (2008: 1-3). This category seems incoherent. Hebrew poetry is an important medium of cultural preservation that employs a formulaic diction. It is conspicuously patterned and sufficiently infectious, even in translation, to inspire a tradition of parallelistic preaching in America (Rosenberg 1970). Free verse is programmatically opposed to traditional diction and to all forms of traditional patterning. It belongs in a different category. I posit a universal category for all patterned verse forms, including lines with syntactic-semantic patterning based on defining characteristics of the sentence. Significant differences among patterned forms are attributable to differing characteristics of the relevant languages and to differing selection of linguistic constituents as prototypes for metrical constituents.

Defining the line as a sequence of syllables makes it impossibly awkward to explain meters that integrate syllabic constraints with strict morphological constraints. In Irish regulated word-foot meter, every verse in a poem must have a fixed number of words, generally two (Travis 1973). The syllabic pattern of the verse changes unpredictably but according to general rules: each pattern must be repeated in one or more adjacent verses, and patterns must be fixed at the level of the word. After a run of verses with two trochaic words, for example, the poet may shift to a run of verses with a trochaic word followed by a stressed monosyllable. The syllabic pattern of the verse has no independent significance. It is a secondary effect of constraints on morphological patterns. Verses and lines in this meter are sequences of words; and every syllable of 
each word is regulated, whether stressed or unstressed. Similar problems arise in Old English meter, which also has foot patterns based on word patterns. What is said about this meter in Fabb and Halle (2008: 263-267) is taken unchanged from an older analysis (Halle and Keyser 1971: 147-164), an analysis that simply brushes aside constraints on unstressed syllables discovered by Sievers and thoroughly validated by Fulk (1992). In saying that Old English meter "systematically ignores unstressed syllables" (2008: 267), Fabb and Halle fail to confront widely acknowledged metrical facts that need to be explained by any theory of the meter. For poetic forms that regulate syllables, Fabb and Halle provide analyses that deserve attention. Their definition of "metrical" cannot serve the needs of universalist metrics, however.

\section{Conclusion}

Ranked violable rules provide ideal formulations for important metrical constraints. Characteristic features of poetic line patterns in SOV, SVO, and VSO meters can be explained by the hypothesis that these line patterns are abstracted from prototypical sentences, as defined within Language Typology. My overarching hypothesis is that metrical constituents are abstracted from linguistic constituents. Since this hypothesis is presented as a universal, the obvious next step is to test it within a larger sample of the world's metrical traditions - something I cannot hope to achieve with the required philological precision. I hope that researchers who work on other meters will find my approach sufficiently promising to try it themselves. 


\section{References}

Carney, James 1989. The dating of archaic Irish verse. In: Tranter, Stephen N.; Tristram, Hildegard L. C. (eds.), Early Irish Literature - Media and Communication / Mündlichheit und Schriftlichkeit in der frühen irischen Literatur. Tübingen: Gunter Narr, 39-55.

Chierchia, Gennaro; McConnel-Ginet, Sally 1990. An Introduction to Semantics. Cambridge, MA: MIT Press.

Cornelius, Ian 2017. Reconstructing Alliterative Verse: The Pursuit of a Medieval Meter. Cambridge: Cambridge University Press.

Dresher, Elan; Lahiri, Aditi 1991. The Germanic foot: metrical coherence in Old English. In: Linguistic Inquiry 22, 251-286.

Dryer, Matthew S. 2007. Word order. In: Shopen, Timothy (ed.), Language Typology and Syntactic Description. $2^{\text {nd }}$ edn., vol. 1 of 3. Cambridge: Cambridge University Press, 61-131.

Fabb, Nigel; Halle, Morris 2008. Meter in Poetry: A New Theory. Cambridge: Cambridge University Press.

Fulk, Robert D. 1992. A History of Old English Meter. Philadelphia: University of Pennsylvania Press.

Fulk, Robert D.; Bjork, Robert E.; Niles, John D. (eds.) 2008. Klaeber's "Beowulf and the Fight at Finnsburg." $4^{\text {th }}$ edn. Toronto: University of Toronto Press.

Greenberg, Joseph H. 1966. Some universals of grammar with particular reference to the order of meaningful elements. In: Greenberg, Joseph H. (ed.), Universals of Language. Cambridge, MA: MIT Press, 73-113.

Halle, Morris; Keyser, Samuel Jay 1971. English Stress: Its Form, its Growth, and its Role in Verse. New York: Harper and Row.

Hayes, Bruce 1983. A grid-based theory of English meter. In: Linguistic Inquiry 14, 357-393.

Kager, René 1999. Optimality Theory. Cambridge: Cambridge University Press.

Kiparsky, Paul 1973. The role of linguistics in a theory of poetry. In: Dædalus 102, 231-244.

Kiparsky, Paul 1977. The rhythmic structure of English verse. In: Linguistic Inquiry 8, 189-247. 
Lehmann, Ruth P. M.; Lehmann, Winfred P. 1975. An Introduction to Old Irish. New York: Modern Language Association of America.

Momma, Haruko 1997. The Composition of Old English Poetry. Cambridge: Cambridge University Press.

Murphy, Gerard 1961. Early Irish Metrics. Dublin: Royal Irish Academy.

Prince, Alan; Smolensky, Paul 2004. Optimality Theory: Constraint Interaction in Generative Grammar. Malden, MA: Blackwell.

Putter, Ad; Jefferson, Judith; Stokes, Myra 2007. Studies in the Metre of Alliterative Verse. Oxford: Society for the Study of Medieval Languages and Literature.

Putter, Ad; Stokes, Myra (eds.) 2014. The Works of the Gawain Poet. London: Penguin.

Rosenberg, Bruce 1970. The Art of the American Folk-Preacher. New York: Oxford University Press.

Russom, Geoffrey 1998. 'Beowulf' and Old Germanic Meter. Cambridge: Cambridge University Press.

Russom, Geoffrey 2009. Some unnoticed constraints on the a-verse in Sir Gawain and the Green Knight. In: Jefferson, Judith; Putter, Ad (eds.), Approaches to the Metres of Alliterative Verse. Leeds: Leeds Texts and Monographs.

Russom, Geoffrey 2011. Word patterns and phrase patterns in universalist metrics. In: Lotman, Mihhail; Lotman, Maria-Kristiina (eds.), Frontiers in Comparative Prosody. Bern: Peter Lang, 337-371.

Russom, Geoffrey 2017. The Evolution of Verse Structure in Old and Middle English Poetry: From the Earliest Alliterative Poems to Iambic Pentameter. Cambridge: Cambridge University Press.

Sievers, Eduard 1893. Altgermanische Metrik. Halle: Niemeyer.

Travis, James 1973. Early Celtic Versecraft: Origin, Development, Diffusion. Ithaca, NY: Cornell University Press.

Watson, Wilfred G. E. 2005. Classical Hebrew Poetry: A Guide to its Techniques. Corrected edn. London: T\&T Clark.

Yakovlev, Nicolay 2008. The Development of Alliterative Meter from Old to Middle English. Diss., University of Oxford.

Youmans, Gilbert 1989. Milton's meter. In: Kiparsky, Paul; Youmans, Gilbert (eds.), Phonetics and Phonology, vol. 1: Rhythm and Meter. San Diego: Academic Press, 341-379. 